\title{
TASAWUF SEBAGAI ETIKA PEMBEBASAN; MEMOSISIKAN ISLAM SEBAGAI AGAMA MORALITAS
}

\author{
Saprin \\ UIN Alauddin Makassar
}

\begin{abstract}
Abstrak
Tujuan dari penelitian ini adalah untuk memahami hakikat tasawuf sebagai etika pembebasan dan bagaimana memosisikan Islam sebagai ajaran moralitas. Latar belakang penelitian ini adalah adanya ketimpangan akibat kemiskinan spiritual yang telah merasuk ke dalam berbagai aspek kehidupan manusia sebagaimana terlihat secara jelas pada kemerosotan bahkan kebangkrutan moral yang berimplikasi pada krisis yang berakibat pada rapuhnya sendi-sendi kehidupan manusia Metodologi yang digunakan dalam penilitian ini adalah pendekatan deskriptif kualitatif. Data dikumpulkan melalui studi literature dan pustaka terkait konsep tasawuf dalam Islam dalam hubungannya dengan pembentukan moralitas manusia. Hasil dari penilitian ini menunjukkan bahwa Tasawuf adalah usaha seseorang untuk mendekatkan diri kepada Tuhan sedekat mungkin. Awal mula timbulnya ajaran tasawuf bersamaan dengan agama Islam itu sendiri yaitu semenjak peristiwa kerasulan Nabi Muhammad SAW. Sebelum Muhammad diangkat menjadi rasul telah berulang kali melakukan Tahannuts dan khalwat di Gua Hira. Ketika menawarkan tasawuf dalam kehidupan modern bukan sebuah tawaran untuk meninggalkan kehidupan dunia yang praktis, melainkan bagaimana kehidupan dunia yang fana' dan praktis itu ditujukan sebagai sarana untuk mencapai ridha dan pengabdian pada Ilahi sehingga yang fana' itu memiliki nilai keabadian, yang keduniawiaan itu memilih dimensi keakhiratan.
\end{abstract}

Kata Kunci: Tasawuf, Islam, Moralitas

\begin{abstract}
The purpose of this study is to understand the nature of Sufism as an ethics of liberation and how to position Islam as a moral teaching. The background of this study is the inequality due to spiritual poverty that has penetrated into various aspects of human life depicted in the decline and even a moral degradation implicating the crisis that result in the fragility of the joints of human life. The methodology used in this research is qualitative descriptive approach. The data were collected through literature studies and libraries related to the concept of Sufism in Islam in relation to the formation of human morality. The results of this study show that Sufism is one's
\end{abstract}


attempt to get closer to God as closely as possible. The beginning of the emergence of the Sufism teachings was started along with the Islamic religion itself since the apostolic event of Prophet Muhammad SAW. Before Muhammad was appointed an apostle, he has repeatedly performed Tahannuts and khalwat in the Hira Cave. When he offered tasawwuf in modern life, was not an offer to abandon the practical life of the world, but how the 'mortal' and practical world life is intended as a means of achieving pleasure and devotion to the Divine. Thus, the mortal 'has the value of immortality, where the mortality chooses the dimension ending.

Keywords: Sufism, Islam, Morality

\section{PENDAHULUAN}

Kegalauan kehidupan spiritual manusia telah menjadi persoalan besar yang perlu diatasi. Tidak terbilang jumlah manusia yang kini menyadari betul pentingnya memenuhi kebutuhan spiritual yang selama ini terabaikan akibat pandangan keliru yang ditebarkan oleh paham materialisme. Ketimpangan akibat kemiskinan spiritual telah merasuk ke dalam berbagai aspek kehidupan manusia sebagaimana terlihat secara jelas pada kemerosotan bahkan kebangkrutan moral. Akibatnya, terjadilah sejumlah krisis yang berakibat pada rapuhnya sendi-sendi kehidupan manusia baik sebagai individu maupun sebagai bagian dari masyarakat.

Islam, sesungguhnya memiliki pandangan yang memosisikan manusia sebagai entitas material sekaligus spiritual. Artinya manusia terbentuk dari unsur material dan spiritual yang terpadu secara harmonis. Pengabaian terhadap dimensi spiritual manusia berakibat pada kesengsaraan manusia itu sendiri, demikian pula sebaliknya. Karena itulah, Islam mengajarkan keharusan bagi setiap orang untuk berusaha memenuhi kebutuhankebutuhannya, baik material maupun spiritual secara berimbang. Sayangnya, kebanyakan manusia lebih tertarik memenuhi kebutuhan materialnya dibanding kebutuhan spiritualnya.

Berdasarkan kenyataan inilah, tasawuf merupakan aspek ajaran etika maupun moral dalam Islam dapat memberikan solusi atas problem spiritualitas dan moralitas manusia dalam kehidupan modernitas. Karena itulah, pendekatan sufistik dalam menghadapi persoalan kehidupan ini 
sangat penting dipertimbangkan.

Berdasarkan deskripsi di atas, penulis memberikan rumusan masalah sebagai berikut: Pertama, Bagaimana pengertian tasawuf sebagai etika pembebasan?; Kedua, Bagaimana memosisikan Islam sebagai ajaran moralitas?

\section{PEMBAHASAN}

\section{Tasawuf Sebagai Etika Pembebasan}

Awal mula timbulnya ajaran tasawuf bersamaan dengan agama Islam itu sendiri yaitu semenjak Muhammad saw, diutus menjadi rasul untuk segenap umat manusia dan seluruh alam semesta. Fakta sejarah menunjukkan bahwa sebelum Muhammad diangkat menjadi rasul telah berulang kali melakukan Tahannuts dan khalwa (Abu Qasim, 2000: 92). di Gua Hira. Disamping untuk mengasingkan diri dari masyarakat Mekah yang mabuk memperturutkan nafsu keduniaan. Juga Muhammad mencari jalan untuk membersihkan hati dan menyucikan jiwa dari noda-noda yang dihinggapi masyarakat pada waktu itu. Mereka ingin lebih dekat dengan Tuhan. Jalan itu diberikan oleh tasawuf (Nasution, 2002:68).

Tasawuf adalah usaha seseorang untuk mendekatkan diri kepada Tuhan sedekat mungkin (Nasution, 2002: 367). dengan melalui penyucian diri dan memperbanyak ibadah di bawah bimbingan guru/syekh (Sahabuddin, 1996: 69). Muhammad Ali berpendapat bahwa tasawuf adalah sifat yang baik. Orang yang memiliki sifat itu adalah sifat yang diperintahkan oleh Allah swt (Valiuddin, 1993:5). Menurut Zakariah al Anzhari, tasawuf adalah cara menyucikan jiwa, tentang cara pembinaan kesejahteraan lahir dan batin untuk mencapai kebahagiaan yang abadi (Musthafa, 1999: 207). Sejalan dengan itu, Hamka mengatakan pada hakikatnya tasawuf adalah kehendak memperbaiki budi dan membersihkan batin (Hamka, 2001:3). Oleh karena itu, orang yang melaksanakan perintah Allah dan menjauhi larangan-Nya adalah orang yang mendekatkan diri kepada-Nya.

Kembali pada persoalan dewasa ini, usaha manusia untuk mengatasi berbagai persoalan, bencana dan malapetaka duniawi tidak menghasilkan kebahagiaan dan kedamaian yang diharapkan. Sebaliknya, justru berakibat 
semakin parahnya nestapa yang diderita. Sebab, setiap penyelesaian masalah justru semakin menjauhkan manusia dari kemanusiaan, juga semakin jauh dari ketuhanan. Hampir seluruh jalan perbaikan hanya mengutamakan bidang material dengan mengabaikan dimensi spiritual dari manusia yang merupakan roh dari peradaban, yaitu tasawuf(Hamzah, 1987: 13). Malapetaka kemanusian itu melanda masyarakat Islam secara luas karena tanpa seleksi masyarakat Islam menggunakan paradigma pemikiran yang materialistik, positivistik dan sekularistik. Dengan demikian, tidak sedikit masyarakat Islam yang mengakibatkan ajaran tasawuf sebagai etika pembebasan yang bersumber dari zat yang Maha Suci, penuntun dan penyejuk hati manusia (Ni'am:7)

Tasawuf bukanlah sesuatu bentuk eskapisme atau melarikan diri dari kehidupan dunia, melainkan sebuah kezuhudan (asketisme) melepaskan diri dari belenggu duniawi. Sebagai contoh, Syaikh Junaidi Al Baghdadi, seorang sufi besar adalah seorang saudagar kaya. Demikian pula Syaikh Abu Hasan Asy-Syadzili, seorang rohaniawan sekaligus petani yang berhasil. Demikian juga Ibnu Hayyan, berhenti melakukan eksprimen-eksprimen fisika guna memenuhi kebutuhan manusia (Niam:14-17). Di situlah tasawuf tampil sebagai kritik sosial dan juga spirit kemajuan sekaligus mengandung nilainilai etika pembebasan.

Ketika menawarkan tasawuf dalam kehidupan modern bukan sebuah tawaran untuk meninggalkan kehidupan dunia yang praktis, melainkan bagaimana kehidupan dunia yang fana' dan praktis itu ditujukan sebagai sarana untuk mencapai ridha dan pengabdian pada Ilahi sehingga yang fana' itu memiliki nilai keabadian, yang keduniawiaan itu memilih dimensi keakhiratan. Inilah urgensi pendekatan sufi agar kegalauan dunia ini bisa diatasi, ketika moralitas memperoleh pijakan dalam kehidupan sehingga bisa ditegakkan dan diamalkan dalam kenyataan.

Berdasarkan hal tersebut, pendekatan tasawuf merupakan tawaran yang perlu dipertimbangkan di abad modern ini lebih menekankan kepada rekonstruksi sosio moral masyarakat sehingga penekanannya lebih intens pada penguatan iman sesuai dengan prinsip-prinsip aqidah Islam dan penilaian terhadap kehidupan duniawi sama pentingnya dengan kehidupan ukhrawi. 


\section{Islam sebagai Agama Moralitas}

Islam, pada hakikatya adalah aturan atau undang-undang Allah yang terdapat dalam kitab Allah dan sunnah rasul-Nya yang meliputi perintahperintah dan larangan-larangan serta petunjuk-petunjuk untuk menjadi pedoman hidup dan kehidupan manusia guna kehidupan di dunia dan akhirat (Pramono dkk., 1992: 15). Secara garis besar, ruang lingkup ajaran Islam meliputi tiga hal pokok, yaitu akidah, syariah dan akhlak (tasawuf).

Sejarah telah membuktikan, bahwa sejak pertama kali dakwah Islam diperkenalkan, dikumandangkan dan disyiarkan maka Islam dari hari ke hari terus merambah, menjelajah, mengembang dan meluas ke seantero dunia. Lantaran kelahiran, Islam memang semata-mata ditujukan untuk seluruh umat manusia agar mereka dapat mewujudkan perdamaian, keselamatan, kesejahteraan dan kebahagiaan yang hakiki, di dunia dan di akhirat. Dengan demikian, Islam bukan hanya untuk kaum Quraisy atau orang Arab saja. Namun dipersiapkan, dirancang dan dipersembahkan bagi seluruh umat manusia semesta alam, sepanjang masa sampai hari kiamat (Khalil, 1992: 15).

Islam merupakan ajaran yang mencakup semua aspek kehidupan. Agama Islam merupakan kekuatan yang pokok dalam perkembangan umat manusia, termasuk perkembangan moral dan etika manusia hingga dewasa ini (Ali, 1999: 41). Itulah sebabnya dimensi moral atau akhlak merupakan hal yang sangat penting dan menjadi perhatian orang dimana saja, baik dalam masyarakat yang telah maju, berkembang maupun yang terbelakang. Karena kerusakan moral atau akhlak dapat mengganggu diri sendiri, masyarakat, bangsa dan negara serta agama. Olehnya itu, kesempurnaan seseorang dalam beragama terletak pada kemampuannya memahami ajaran Islam secara mendalam sehingga dia bersifat arif dalam menjalankan syariat Islam.

Berdasarkan hal tersebut, ajaran Islam merupakan agama moralitas berfungsi sebagai pelindung yang memberikan keteduhan dan kesejukan serta memiliki ketentraman hidup (Nashir, 1999: 41). Dengan demikian, ajaran agama Islam mencakup berbagai dimensi kehidupan manusia (multi dimensional) senantiasa dapat menyesuaikan diri dengan perkembangan dan tidak pernah mengenal istilah ketinggalan zaman. Jadi moralitas Islamiyah mengatur prikehidupan manusia semasa di dunia untuk hidupnya di dunia 
maupun persiapan ke alam akhirat. Perwujudan nilai moralitas oleh Islam disebut amal shaleh (Achmad : 125).

\section{PENUTUP}

Berdasarkan uraian di atas, penulis menarik dua kesimpulan. Pertama, Tasawuf bukanlah sesuatu bentuk eskapisme atau melarikan diri dari kehidupan dunia, melainkan sebuah kezuhudan (asketisme) melepaskan diri dari belenggu duniawi. Tasawuf tampil sebagai kritik sosial dan juga spirit kemajuan sekaligus mengandung nilai-nilai etika pembebasan. Dengan demikian, pendekatan sufistikmerupakantawaran yang perlu dipertimbangkan di abad modern ini lebih menekankan rekonstruksi sosiomoral masyarakat dengan berdasarkan prinsip-prinsip akidah Islam. Kedua, Ajaran Islam yang merupakan agama moralitas berfungsi sebagai pelindung yang memberikan keteduhan dan kesejukan serta memiliki ketentraman hidup. Islam mencakup berbagai dimensi kehidupan manusia (multi dimensional) senantiasa dapat menyesuaikan diri dengan perkembangan dan tidak mengenal ketinggalan zaman. Perwujudan moralitas Islamiyah adalah amal shaleh.

\section{DAFTAR PUSTAKA}

Achmad, Mudlor. Etika Islam. Surabaya: Al Ikhlas.

Ali, Mukti. Memahami Beberapa Aspek Ajaran Islam. Bandung: Mizan, 1991.

Hamka. Tasawuf Modern. Jakarta: Pustaka Panjimas, 2001.

Khalil, Imanuddin. Khaula Intisyaril Islam Waqoo’i WaMulaa Khadhoat, Ter. Ahmad Sukarno, Islam dari Masa ke Masa. Jakarta: Fikahati Aneska, 1992.

Musthafa.Akhlak Tasawuf. Bandung: Pustaka Setia, 1999.

An Naisabury, Abu Qasim Al Qusyairy.Ar-Risalatul Qusyairiyah fi 'Ilmi AtTashawwufi, Terj. Muhammad Lukman Hakim, Risalatul Qusyairiyyah, Induk Ilmu Tasawuf. Surabaya: Risalah Gusti, 2000.

Nashir, Haidar.Agama dan Krisis Kemanusiaan Modern. Yogyakarta: Pustaka Pelajar, 1999.

----.-. Islam Rasional: Gagasan dan Pemikiran. Bandung: Mizan, 1996.

Nasution, Harun.Islam Ditinjau dari Berbagai Aspeknya.Jilid II. Jakarta: Universitas Indonesia (UI-Pres), 2002.

Niam, Syamsun. Wasiat Tarekat Hadratus Syaikh Hasyim Asyari. Jogyakarta: Ar 
Ruzz Media, 2011.

Pramono, Wahyu, dkk.Etika Membangun Masyarakat Islam Modern. Yogyakarta: Pustaka, Pelajar, 2007.

Sahabuddin. Metode Mempelajari Ilmu Tasawuf (Menurut Ulama Sufi). Surabaya: Media Varia Ilmu, 1996.

Valiuddin, Mir.Tasawuf dalam Al Quran. Jakarta: Pustaka Firdaus, 1993.

Ya'qub, Hamzah. Tashawwuf dan Taqarrub Tingkat Ketenangan dan Kebahagiaan Mukmin. Bandung: Pustaka Madya, 1987. 